\title{
Making mathematics accessible to all
}

Last update: 17 March 2017

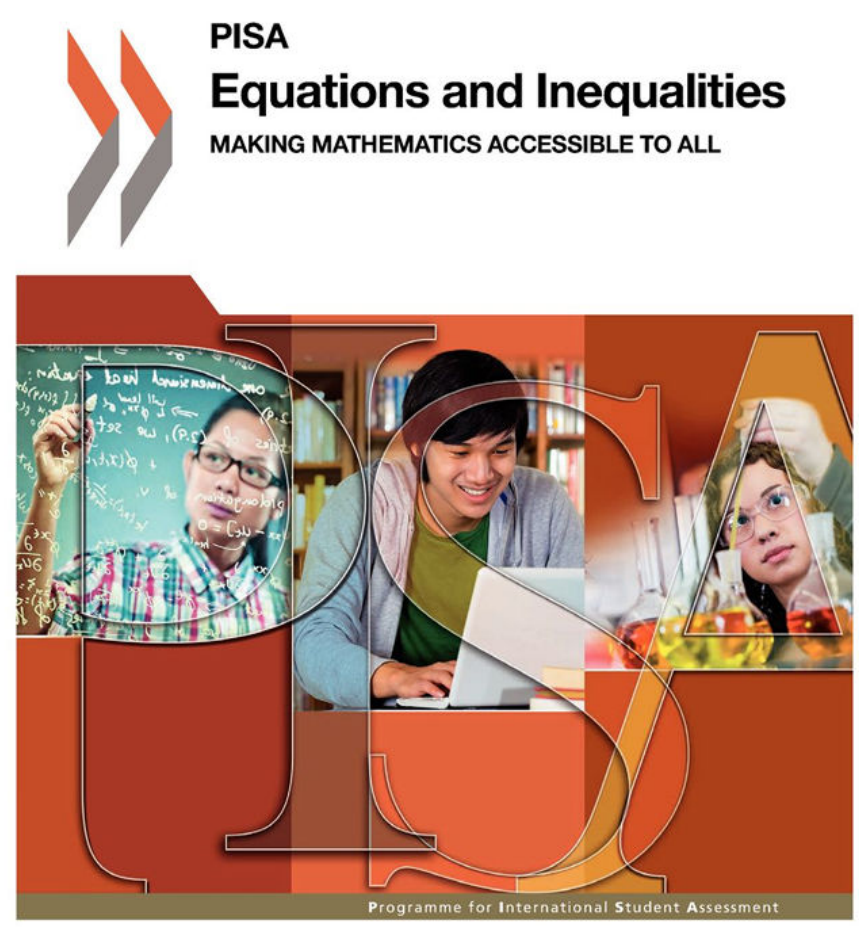

\section{(2)) OECD}

Do you know what an arithmetic mean is? Or a polygon? On average, fewer than $30 \%$ of students across OECD countries understand the concept of an arithmetic mean, while less than $50 \%$ are comfortable with elementary geometrical shapes known as polygons. Yet with numeracy skills needed more than ever in the work place, today's students should be able to compute, engage in logical reasoning and use mathematics to tackle novel problems. However, only a minority of 15 -year-old students in most countries grasp and can work with core mathematical concepts. To what extent can teachers and schools break this pattern?

Equations and Inequality: Making Mathematics Accessible to All suggests that one way forward is to ensure that all students spend more quality or "engaged" time 
learning core mathematics concepts and solving challenging mathematics tasks. According to the report, based on results from PISA 2012, education systems have done well in providing equitable access to the quantity of mathematics education, but differences in quality remain. While well-off students are taught to think like mathematicians, disadvantaged pupils tend to be exposed to simple facts and figures only. The relationship between content and socio-economic profiles is even stronger in countries that track students early into different study programmes, that have larger percentages of students in selective schools, and that transfer less-able students to other schools. Over $95 \%$ of students in Australia, Ireland, Israel and the UK attend schools where students are grouped by ability for mathematics classes.

Policy makers could develop more ambitious and coherent mathematics standards that cover core mathematical ideas in depth, the report suggests. Another path would be to reduce tracking and stratification among schools. Teachers could also help by replacing routine tasks with challenging problems, support positive attitudes towards mathematics and offer tailored support to struggling students.

Visit www.oecd.org/pisa and www.oecd.org/education

\section{References}

Equations and Inequalities http://dx.doi.org/10.1787/9789264258495-en 